\title{
Cádmio, Chumbo e Solubilidade do Fósforo em Suplementos Minerais Bovinos Comercializados em Goiás
}

José R. Gonçalves, Renata M. Gonçalves \& Raniery M. Gonçalves

Visando baratear custos, algumas indústrias de sal mineral utilizam matérias-primas inferiores. Assim, algumas formulações podem estar contaminadas, necessitando controle constante. Objetivou-se determinar cádmio, chumbo e solubilidade do fósforo em amostras das mesorregiões de Goiás, no laboratório do Centro de Pesquisas em Alimentos - UFG. Utilizou-se espectrofotometria de absorção atômica nas análises. Não houve diferença significativa entre chumbo e a solubilidade do fósforo nesses suplementos, ao contrário do cádmio. Os suplementos minerais encontraram-se com concentrações de chumbo e cádmio superiores às normas vigentes. A baixa solubilidade do fósforo na maioria dos suplementos sugere uso de fontes não convencionais deste elemento.

Palavras-chave: absorção atômica, metais pesados, sal mineral.

Aiming to lower costs, some industries using mineral raw materials lower. Thus, some formulations may be contaminated, requiring a constant control. The objective was to determine cadmium and lead solubility of phosphorus in samples mesoregion of Goias, in the laboratory of the Research Center for Food - UFG. We used atomic absorption spectrophotometry in the analysis. There was no significant difference between lead and the solubility of phosphorus in these supplements, unlike cadmium. Mineral supplements are concentrations of cadmium and lead to higher standards. The low solubility of phosphorus in most supplements suggests use of unconventional sources of this element.

Keywords: atomic absorption, heavy metals, mineral supplement. 


\section{Introdução}

O Estado de Goiás, localizado no Planalto Central do Brasil, possui uma população de bovinos de quase 21 milhões de animais ${ }^{1}$, a maioria gado para corte, o que propicia um atraente campo de negócios para os que sobrevivem da cria, recria e engorda dos animais. Entretanto, grande parte do solo goiano é pobre em elementos minerais, particularmente fósforo, cobre e cobalto. Isto obriga os fazendeiros a suplementarem seus animais durante o ano com misturas de suplementos minerais. Por esta razão, a comercialização de formulações minerais é muito intensa, constituindo-se em um mercado altamente competitivo.

Visando baratear custos para ganhar mercado e garantir suas vendas, algumas indústrias produtoras e/ou misturadoras de sal mineralizado para bovinos, utilizam fontes de matérias-primas escolhidas em função do menor preço. Assim, acredita-se que algumas formulações minerais possam estar contaminadas por elementos tóxicos, sobretudo metais pesados e substâncias radioativas que prejudicam inclusive o meio ambiente. Essa suspeita, aliada ao fato de que o governo brasileiro no ano de 2000 por meio do Ministério da Agricultura, Pecuária e Abastecimento (MAPA) ${ }^{2}$ liberou o uso de fontes alternativas de fósforo a partir de fosfatos de rochas, fez perceber a necessidade de se monitorar as misturas minerais destinadas ao consumo animal revendidas em qualquer estado do país, incluindo Goiás.

Do ponto de vista econômico, diferentes autores destacam que os metais pesados quando presentes em suplementos alimentares para animais, podem causar alterações orgânicas importantes, prejudicando o desempenho dos animais ${ }^{3,4}$. Segundo Marçal et al. ${ }^{5}$, suplementos minerais com controle restrito de qualidade por parte dos fabricantes, fosfatos de rocha e fosfatos agrícolas, podem conter concentrações de metais pesados suficientes para causarem alterações clínicas importantes em bovinos, principalmente de ordem reprodutiva, como é o caso do cádmio que pode causar degeneração testicular ou aciclia quando em concentrações elevadas no aparelho reprodutor.

O chumbo foi considerado por muitos estudiosos como o elemento químico inorgânico de maior risco à saúde dos animais de criação, particularmente a espécie bovina ${ }^{5-8}$, o que também representa riscos à saúde pública. O cádmio nos alimentos, de maneira geral, apresenta-se em menor concentração, todavia é extremamente nocivo e cumulativo a exemplo do chumbo ${ }^{9}$.

Problemas nutricionais, como deficiência, toxicidade e desequilíbrio mineral, causam anualmente elevados prejuízos à pecuária nacional. Em qualquer região, um dos principais problemas do desenvolvimento da pecuária é o suprimento contínuo de uma boa alimentação dos animais, que requer cuidado constante ${ }^{10}$. Os nutrientes requeridos pelos ruminantes podem ser agrupados nas seguintes categorias: água, energia, proteína, vitaminas e minerais. Todavia, deficiências minerais ou desequilíbrio no solo e nas forrageiras, em muitas regiões, têm sido responsáveis pela baixa reprodução e inadequada produtividade de diversas regiões brasileiras, incluindo Goiás ${ }^{11}$. Bovinos em pastagens com severa deficiência em fósforo podem apresentar perdas superiores àquelas observadas em animais que estão em pastagens deficientes em energia ou proteína ${ }^{8}$.

Pesquisas realizadas sobre a importância da suplementação mineral em regiões tropicais têm mostrado aumento de $20 \%$ a $100 \%$ na porcentagem de nascimento de bezerros, de $10 \%$ a $25 \%$ na taxa de crescimento e redução significativa do índice de mortalidade. Existem pelo menos 15 minerais essenciais para a nutrição dos bovinos: sete macro-nutrientes (cálcio, fósforo, potássio, sódio, cloro, magnésio e enxofre) e oito micronutrientes (ferro, cobre, zinco, iodo, manganês, cobalto, molibdênio e selênio), sendo que em qualquer região poderá haver concentrações consideradas tóxicas e deficiência notória de fósforo, causando redução na produção e produtividade do animal ${ }^{5}$. Ressalta-se que um fosfato com o mesmo nível de fósforo determinado em análises químicas, pode não suprir a mesma quantidade de fósforo do ponto de vista biológico. A diferença em valor biológico entre vários compostos minerais pode ser numericamente medida, e os valores podem ser aplicados ao cálculo das misturas minerais ${ }^{12}$.

Nunes et al. ${ }^{13}$ afirmaram que quando a absorção intestinal é baixa, o nível de fósforo na urina se reduz. Para manter a concentração no sangue ocorre aumento na reabsorção de fósforo nos túbulos renais, chegando próximo a $99 \%$.

Assim, torna-se necessário analisar as várias fontes 
de suplementos minerais para macro e microelementos, não só sob o ponto de vista de sua composição, mas também em relação à sua biodisponibilidade, haja vista a expressiva diferença de custos entre as fontes de baixa e alta disponibilidade ${ }^{14}$. A inclusão de fosfatos com altos teores de flúor na dieta animal resulta em menor ganho de peso, menor ingestão de alimentos, pior conversão alimentar e comprometimento da mineralização óssea e da resistência óssea às fraturas. Já os fosfatos "feedgrade" apresentam alto grau de pureza química e alta biodisponibilidade de fósforo ${ }^{15}$.

Cálcio e fósforo estão intimamente correlacionados, chegando ao ponto em que a deficiência ou o excesso de um pode interferir na utilização do outro. Quando cálcio e fósforo são fornecidos para ruminantes em proporções adequadas, ou seja, $2: 1(\mathrm{Ca} / \mathrm{P})$, e em formas eficientemente aproveitáveis, tem-se então uma ótima utilização dos dois elementos. Aproximadamente 99\% do cálcio existente no organismo encontram-se nos ossos e nos dentes. Portanto, o cálcio é um elemento essencial na constituição de todas as células vivas e quando há deficiência de cálcio, os animais em crescimento apresentam problemas como deformações ósseas e fraturas ${ }^{16}$.

Em contraste com o fósforo, que é o segundo elemento mineral encontrado em maior concentração no organismo animal, a deficiência de cálcio em gado de corte é raramente observada. Mais de $80 \%$ do fósforo se encontra associado ao cálcio nos ossos (na forma de hidroxiapatita, fluoroapatita) e nos dentes, enquanto cerca de $20 \%$ localiza-se nos tecidos moles do corpo $^{17}$. Daí se percebe a importância de suplementação dos dois minerais citados.

O fósforo tem função importante no metabolismo energético, na formação dos fosfolipídios e está presente nas células vivas, na microbiota do rúmen, participando na conversão do caroteno para vitamina A e em vários outros processos orgânicos importantes do bovino. Em casos de deficiência, os animais desenvolvem uma condição conhecida como "apetite depravado", com várias consequências, desde a fragilidade óssea, até a diminuição da fertilidade e produtividade - tanto de carne quanto de leite ${ }^{18}$.

Os ossos também são reservas de cálcio e fósforo que podem ser mobilizados ocasionalmente quando a assimilação desses minerais é inadequada para atender às necessidades do organismo. No caso do animal produtivo receber dietas deficientes, as glândulas paratireóides através do paratormônio mobilizam estes elementos dos ossos para suprir as necessidades. Essa condição poderá se agravar quando o animal estiver recebendo dieta de suplementos minerais com alta concentração de impurezas, a exemplo do chumbo, cádmio e outros, podendo interagir com os mesmos, deslocando-os do sitio de atividade biológica ${ }^{11}$.

Sabe-se que óxido de zinco, óxido de magnésio, óxido de ferro e calcário dolomítico são fontes potenciais de chumbo e cádmio, além de possuírem baixa biodisponibilidade. E deve ser considerado o percentual utilizado desses suplementos nas misturas minerais em relação ao fósforo, que é utilizado em maior concentração se comparado às fontes de microelementos ${ }^{19}$.

Voltada para a produção de proteína animal destinada à alimentação humana, a nutrição animal torna-se um elo importantíssimo do agronegócio ${ }^{20}$. Vale lembrar que os componentes mais importantes no cálculo de uma mistura mineral estão relacionados com os níveis de suplementação utilizados de cada mineral a ser oferecida por animal ${ }^{21}$.

A ausência de planejamento urbano adequado tem ocasionado o crescimento desordenado em alguns estados brasileiros, como em Goiás, com consequências indesejáveis aos animais de exploração pecuária, afetando a absorção de nutrientes através do consumo e contato com o ambiente poluído com substâncias tóxicas diversas, a exemplo do cádmio e chumbo. Localidades rurais que anteriormente serviam somente como habitats para criação de animais de produção, hoje dividem espaço com fábricas e indústrias que poluem o ar, o solo, as plantas e os mananciais hídricos, tornando os seres vivos vulneráveis à toxidade de seus efluentes ${ }^{18}$. Percebe-se a importância do meio ambiente isento de contaminações e a necessidade de um controle maior dos produtos obtidos, para resultar em uma qualidade de vida saudável aos seres vivos em geral, incluindo os bovinos e o homem.

Nesse aspecto, reforça-se que as pesquisas com metais pesados cádmio, chumbo e suplementos minerais em Goiás e no país ainda são escassas, o que se percebe pela literatura científica reduzida e desatualizada. Por isso, constituiu-se objetivo principal deste estudo determinar os teores de cádmio, chumbo e a solubilidade 
do fósforo em ácido cítrico a $2 \%$ e observar a proporção de fontes alternativas do fósforo em suplementos minerais destinados à formulação e elaboração de sais minerais e misturas prontas de diferentes marcas comerciais para o consumo bovino.

\section{Material e métodos}

\section{Amostragem}

Um total de 50 amostras de suplementos e misturas minerais foi colhido ao acaso, diretamente do estoque disponível em estabelecimentos comerciais, além de propriedades rurais colaboradoras pertencentes aos municípios localizados nas cinco mesorregiões de Goiás (Noroeste, Norte, Centro, Leste e Sul), de acordo com o Anuário Estatístico do Estado de Goiás ${ }^{22}$. Cada amostra com quantidade em torno de $200 \mathrm{~g}$, de marca e tipo diferentes de suplementos minerais, foi acondicionada em recipiente transparente de polietileno previamente lacrado e identificado. As análises foram efetuadas no Laboratório do Centro de Pesquisa em Alimentos CPA, da Escola de Veterinária da Universidade Federal de Goiás e no Laboratório Nacional Agropecuário (LANAGRO-GO) do Ministério da Agricultura, Pecuária e Abastecimento de Goiás (MAPA).

\section{Métodos analíticos}

Na metodologia analítica empregada para a determinação do cádmio e chumbo em sal mineralizado e suplementos minerais, as amostras foram previamente submetidas a secagem a $60^{\circ} \mathrm{C}$ por aproximadamente 12 horas. A digestão e a solubilização foram realizadas com ácido nítrico, perclórico e clorídrico, fazendo-se a filtração em papel de filtro, filtração média, diâmetro $12,5 \mathrm{~cm}$ para balão volumétrico de $50 \mathrm{~mL}$ e diluições apropriadas, de acordo com a curva padrão específica para cada elemento em estudo. Foi feita determinação do cádmio e chumbo por espectrometria de plasma induzido, empregando-se um equipamento modelo ICP-AES (Vista-MPX) Varian SP de alta sensibilidade no LANAGRO-GO/MAPA. O cádmio e o chumbo foram separados da amostra por concentração com pirrolidinaditiocarbamato de amônia (ADPC), P. A. com pH 2,3 $\pm 0,1^{9,23,24}$.

Todas as análises foram realizadas em duplicatas. Para a análise estatística dos dados, utilizou-se o SAS/ BASIC Program ${ }^{25}$.

\section{Preparo para as análises de chumbo e cádmio}

O preparo da solução padrão para a construção da curva padrão, utilizando-se chumbo e cádmio metálico Merck, grau de pureza EAA (99,99\%), foi realizado da seguinte forma: dissolveu-se separadamente $1,0 \mathrm{~g}$ de chumbo e cádmio metálico em ácido nítrico 50\%, completando-se o volume com água destilada deionizada para $1000 \mathrm{~mL}$, para obter concentração de 1000mg/L. Desta solução, fez-se outra intermediária de $50 \mathrm{mg} / \mathrm{L}$ como estoque. A partir desta solução intermediária, prepararam-se diluições para a curva padrão de ajuste do equipamento nas concentrações de 1,0 mg/L; 2,0 mg/L; 3,0 mg/L para o chumbo e 0,20 mg/L; 0,40 mg/L; 0,80 $\mathrm{mg} / \mathrm{L}$ para o cádmio em balões volumétricos de $50 \mathrm{~mL}$, completando-se o volume com ácido clorídrico 0,5 N, de maneira que padrões e amostras tivessem as mesmas condições finais de concentração e pH no momento da leitura. As condições do equipamento para procedimento da leitura de padrões e amostras estão na Tabela 1.

Tabela 1. Condições para determinação de chumbo e cádmio em Espectrômetro de Absorção Atômica, modelo GBC AA 932, Estado de Goiás.

\begin{tabular}{|l|c|c|}
\hline Elemento / Condições do Aparelho & Chumbo & Cádmio \\
\hline Comprimento de onda (nm) & 217,0 & 228,8 \\
\hline Tempo de leitura (s) & 0,5 & 0,5 \\
\hline Fenda (nm) & 1,0 & 0,5 \\
\hline Fluxo de acetileno (mL/min) & 13 & 13 \\
\hline Fluxo de ar (mL/min) & 30 & 30 \\
\hline Corretor de background & sim & sim \\
\hline Chama estequiométrica & Oxidante & Oxidante \\
\hline Sensibilidade típica (mg/L) & 0,016 & 0,007 \\
\hline Corrente da lâmpada (mA) & 5,0 & 3,0 \\
\hline
\end{tabular}

\section{Procedimentos}

As amostras foram preparadas e homogeneizadas com um quarteador tipo Jones de oito saídas. Ao separar uma porção menor, procedeu-se nova homogeneização utilizando moinho tipo Willey e peneira com granulometria de $0,50 \mathrm{~mm}$, ambos em aço inoxidável, obtendo-se amostra homogênea e isenta de contaminantes metálicos. As amostras assim preparadas foram analisadas em conformidade com a metodologia proposta em Métodos de Análise de Resíduos Biológicos em alimentos para uso animal, também adotado pelo 
Departamento de Agricultura dos Estados Unidos e a Associação Nacional dos Fabricantes de Rações e suplementos minerais ANFAR/MAPA ${ }^{26}$.

\section{Digestão das amostras}

Após o preparo e homogeneização, as amostras foram completamente mineralizadas por tratamento pela via úmida. Para tanto, pesou-se em torno de 5,0 g de amostra em becker de vidro de $125 \mathrm{~mL}$, adicionouse $10 \mathrm{~mL}$ de ácido nítrico P. A. e submeteu-se a fervura em chapa aquecedora a temperatura controlada de $200^{\circ} \mathrm{C}$ até o desprendimento de fumos amarelados. Em seguida, acrescentou-se 2,0 mL de ácido perclórico P. A., aqueceuse até a completa destruição da matéria orgânica por 20 minutos aproximadamente. Procedeu-se o abaixamento da temperatura e filtrou-se quantitativamente em balão volumétrico de $50 \mathrm{~mL}$, completando-se o volume com água destilada deionizada. Posteriormente, foram preparadas as diluições específicas para cada elemento a ser determinado. As diluições obtidas foram analisadas por espectroscopia de plasma induzido ICP-OES.

Paralelamente, foram realizados testes de recuperação e branco. A curva padrão específica dos elementos em análise foi obtida, o espectrômetro foi otimizado, e as leituras do branco, dos padrões e das amostras foram realizadas.

Quando necessário, as amostras foram diluídas para que se obtivessem leituras dentro da faixa ótima de trabalho. As alíquotas foram diluídas em solução de ácido clorídrico 0,5 N, para manter as mesmas condições de $\mathrm{pH}$ e viscosidade.

Simultaneamente, a cada grupo de amostra analisada foi efetuado o teste de recuperação e branco, fortificando-se uma amostra com teor conhecido do elemento pesquisado. Preparou-se uma curva padrão específica para os elementos analisados e otimizou-se o equipamento, fazendo a leitura do branco, dos padrões e das amostras. Foram calculados os resultados das amostras, bem como a porcentagem de recuperação e o coeficiente de correlação (r) para verificar a exatidão do método. Para verificar interferências químicas e/ ou espectrais, usou-se regressão linear ${ }^{27}$.

\section{Vidrarias e reagentes}

Utilizou-se vidraria de uso comum em laboratório, as quais passaram pelas seguintes etapas de limpeza e desmineralização de elementos contaminantes: banho com solução de hipoclorito de sódio, alta pureza, concentração 1:2000 (v/v); lavagem com detergente neutro, grau de pureza AA a $2 \%$ e água deionizada, seguida por enxágüe com água deionizada; banho em solução de ácido clorídrico grau AA a 0,5 N (v/v) e finalmente, enxágue com água deionizada.

Foram utilizados reagentes usuais para ICP-OES (espectrometria de plasma induzida), tais como ácido nítrico e ácido clorídrico Spectrosol de qualidade para análise, padrões próprios de cada elemento e ampolas de titrisol, grau de pureza ICP-OES.

\section{Procedimento para determinação do fósforo total e da solubilidade do fósforo em ácido cítrico a $\mathbf{2 \%}$}

Procedeu-se a determinação da porcentagem do fósforo total e da solubilidade do fósforo em ácido cítrico a $2 \%$ por espectrofotometria UV, na faixa do visível, empregando-se um equipamento modelo Perkin Elmer/Lambda 25, duplo feixe de alta sensibilidade, pertencente ao Centro de Pesquisas em Alimentos - CPA/ UFG. A extração do fósforo nas amostras foi realizada conforme metodologia ANFAR/MAPA ${ }^{26}$. Após preparo e homogeneização, a matéria orgânica da amostra foi completamente destruída por tratamento pela via úmida com ácido nítrico. Para tanto, pesou-se em torno de 1,0 g de amostra em Becker de vidro de $125 \mathrm{~mL}$, adicionouse $10 \mathrm{~mL}$ de ácido nítrico P. A. e submeteu-se a fervura em chapa aquecedora a temperatura controlada de $200^{\circ} \mathrm{C}$ até o desprendimento de fumos amarelados. Em seguida, acrescentou-se 2,0 mL de ácido perclórico P. A. e aqueceu até a completa destruição da matéria orgânica por 20 minutos aproximadamente. Procedeu-se o abaixamento da temperatura e filtrou-se quantitativamente para balão volumétrico de $100 \mathrm{~mL}$, completando-se o volume com água destilada deionizada. Posteriormente, foram preparadas diluições específicas para o elemento a ser determinado. As diluições obtidas foram analisadas por espectrofotometria de UV na faixa do visível, utilizandose comprimento de onda na faixa de $420 \mathrm{~nm}$.

Para a extração do fósforo solúvel, utilizou-se 100 $\mathrm{mL}$ de ácido cítrico P. A. a $2 \%$, nas quantidades de 100 $\mathrm{mL}$ por amostra sob agitação controlada de 30 rpm - 40 rpm em agitador tipo Wagner por 30 minutos. Após a 
extração, fez-se a filtração da amostra quantitativamente em balão volumétrico de $200 \mathrm{~mL}$. A seguir, tomou-se uma alíquota de 1,0 mL e verteu-se em balão volumétrico de $50 \mathrm{~mL}$ conforme o teor esperado de fósforo na amostra. Posteriormente adicionou ao balão volumétrico de $50 \mathrm{~mL}$, $10 \mathrm{~mL}$ da mistura de partes iguais de solução de molibdato de amônio 5\% e metavanadato de amônio 0,25\%, completando-se o volume com água destilada deionizada e deixando a solução em repouso por 10 minutos para reação. Preparou-se um branco e padrões nas concentrações de 4,0 $\mathrm{mg} / \mathrm{L}$, 8,0 mg/L, 12,0 mg/L e 16,0 mg/L. Fez-se a leitura do branco e dos padrões e construiu a curva de calibração para calcular a equação de regressão linear. A leitura das absorbâncias das amostras e padrões foi realizada em espectrofotômetro com comprimento de onda regulado a $420 \mathrm{~nm}$. Os resultados das concentrações de fósforo e da percentagem de solubilidade foram calculados em relação às diluições e a massa da amostra, comparando-as com a curva de calibração, usando a equação de regressão linear para calcular a concentração final.

\section{Análise Estatística}

Foram calculados os parâmetros de tendência central (média e mediana) e de dispersão, desvio padrão, coeficiente de variação, valores máximo e mínimo dos teores de cádmio e chumbo, e a porcentagem de solubilidade do fósforo em suplementos minerais de cada mesorregião. Os teores médios entre as mesorregiões foram comparados pelo teste de Tukey $(\mathrm{P}<0,05 \%)$.

A regressão linear foi aplicada entre as leituras dos padrões, com o intuito de verificar a exatidão em relação às leituras das amostras, estabelecendo a dispersão das médias e desvio padrão em relação à curva de calibração específica para cada elemento em estudo ${ }^{28}$.

\section{Resultados e discussão}

Os resultados da análise de variância, empregando o delineamento inteiramente ao acaso para três variáveis, ou seja, os teores de chumbo e cádmio e a solubilidade de fósforo em sal mineral estão na Tabela 2. Observouse que apenas a variável cádmio apresentou diferença significativa entre as mesorregiões.

A não significância para o chumbo e a solubilidade de fósforo entre as mesorregiões indica uma homogeneidade em relação à mistura mineral utilizada na alimentação de bovinos. Ressalta-se que a qualidade dos suplementos minerais está normalmente distribuída em todas as mesorregiões do Estado de Goiás, ou seja, pode existir uma padronização em relação à alimentação do rebanho bovino entre as regiões Goianas, à variável chumbo e à solubilidade de fósforo.

Tabela 2. Análise de variância segundo o delineamento inteiramente ao acaso para os teores de chumbo, cádmio e solubilidade de fósforo em sal mineral das cinco mesorregiões do Estado de Goiás.

\begin{tabular}{|c|c|c|c|c|}
\hline \multirow{2}{*}{ FV } & \multirow{2}{*}{ GL } & \multicolumn{3}{|c|}{ Quadrado Médio } \\
\cline { 3 - 5 } & & Cd & Pb & $\begin{array}{c}\text { Solubilidade } \\
\text { de } \mathbf{P}\end{array}$ \\
\hline Mesorregião & 4 & $27,5035^{*}$ & $11267,2309 n \mathrm{~ns}$ & $119,7288 \mathrm{~ns}$ \\
\hline Resíduo & 45 & 8,9908 & 1084,8810 & 277,2202 \\
\hline
\end{tabular}

ns: Não significativo a $5 \%$ de probabilidade. $*$ Significativo a $5 \%$ de probalidade.

Os dados relativos aos teores médios de chumbo, cádmio e solubilidade do fósforo determinados em suplementos e misturas minerais para bovinos no Estado de Goiás, encontram-se nas Tabelas 3, 4 e 5.

Tabela 3. Teores de chumbo (mg/Kg) em suplementos minerais para bovinos comercializados, Estado de Goiás.

\begin{tabular}{|c|c|c|c|c|c|}
\hline Parâmetro * & \multicolumn{5}{|c|}{ Mesorregião } \\
\hline & Noroeste & Norte & Centro & Leste & Sul \\
\hline Média & $38,8 * a$ & $30,33 * a$ & $45,23 * a$ & $40,07 * a$ & $112,7 * a$ \\
\hline $\begin{array}{l}\text { Desvio } \\
\text { padrão }\end{array}$ & 11,4 & 19,0 & 36,0 & 16,4 & 30,0 \\
\hline CV (\%)b & 71,9 & 76,0 & 75,9 & 51,2 & 61,9 \\
\hline Mediana & 25,6 & 24,8 & $48,0^{*}$ & $32,5^{*}$ & $77,2^{*}$ \\
\hline $\begin{array}{c}\text { Amplitude } \\
\text { total }\end{array}$ & $46,2 *$ & $46,5^{*}$ & $240,0^{*}$ & 18,0 & $153,6^{*}$ \\
\hline Mínimo & 2,50 & 1,55 & 0,33 & $22,94 *$ & 0,38 \\
\hline Máximo & $48,7 *$ & $48,0 *$ & $240,0^{*}$ & $41,0 *$ & $154,0 *$ \\
\hline
\end{tabular}

*Teores acima do $\mathrm{LMR}^{4,7}$. ${ }^{\text {aEm }}$ uma mesma linha, valores seguidos de uma mesma letra não diferem significativamente entre si (Tukey, $\mathrm{p}<$ $0,05) .{ }^{\text {b }} \mathrm{CV}=$ coeficiente de variação.

\section{Chumbo}

Nota-se a partir da Tabela 3, que não houve diferença significativa $(\mathrm{P}>0,05)$ entre as médias de chumbo em suplementos minerais comercializados em Goiás. Os níveis médios encontrados nas mesorregiões Centro, Leste e Sul Goiano estão acima do LMR (Limite Máximo 
de Resíduos) estabelecido pelo $\mathrm{NRC}^{7}$, que é de 30,0 mg/ Kg. Mas em relação ao recomendado por Maletto ${ }^{3}$, que é $10,0 \mathrm{mg} / \mathrm{Kg}$, os teores médios de todas as mesorregiões estão acima. Ao se comparar os resultados deste estudo com os apresentados por Marçal et al. ${ }^{11}$, ficou evidente que as misturas de sal mineralizado utilizadas para alimentação de bovinos encontram-se contaminadas com substâncias inorgânicas, chumbo e cádmio em concentrações superiores àquelas citadas na literatura e estabelecidas na Legislação Internacional.

A mediana também apresentou resultado elevado, semelhante ao teor médio entre os municípios amostrados. Por outro lado, o maior valor obtido em duas amostras, sendo uma na mesorregião Centro Goiano 240,0 mg/ Kg e outra no Sul Goiano 154,0 mg/Kg, revelaram-se teores elevados, mas abaixo dos níveis obtidos por outro estudo $^{29}$, que encontraram valores variando de 16,0 $\mathrm{mg} / \mathrm{kg}$ a 625,0 mg/Kg para valores mínimo e máximo, respectivamente. No presente estudo os teores de chumbo variaram de 0,33 mg/Kg, valor mínimo, a 449,0 mg/Kg, valor máximo.

Segundo Gonçalves ${ }^{9}$, a suspeita da presença de metais pesados recai sobre as fontes de macro e microelementos incorporados às misturas minerais, especialmente fósforo, tendo em vista que este mineral representa o maior custo na composição de um sal mineral. Por isso, alguns fabricantes buscam esse elemento essencial em fontes alternativas, de menor custo e de baixa solubilidade, a exemplo dos fosfatos naturais de rochas e fosfatos agrícolas, misturando-os em diferentes proporções, como demonstraram os dados do presente estudo. Isso pode ser observado ao analisar os resultados que apresentaram baixo teor médio de solubilidade do fósforo nos suplementos minerais analisados. Coincidentemente, essas foram amostras que apresentaram maiores teores de metais pesados, notadamente o chumbo.

Dentre as mesorregiões estudadas, a Centro e Sul Goianos, foram as que apresentaram os maiores teores de chumbo nos suplementos minerais comercializados em Goiás (Tabela 3). Essa constatação sugere que os suplementos minerais comercializados nessas mesorregiões possuem em suas formulações ingredientes ricos em impurezas e de baixa qualidade. Além das fontes de fósforo com baixa biodisponibilidade utilizadas em maior proporção na elaboração das misturas, há que se considerar a questão das fontes de zinco (óxido de zinco), ferro (óxido de ferro), magnésio (óxido de magnésio) e manganês (óxido de manganês), apesar de utilizadas em menores proporções na formulação das misturas, que podem ser fontes potenciais de chumbo e cádmio, e são largamente utilizadas em substituição aos sulfatos de zinco e outros, em função de seu menor custo para baratear o produto final ${ }^{30}$.

Das 50 amostras de suplementos minerais analisadas, $52,0 \%$ apresentaram valores de chumbo acima dos 30 $\mathrm{mg} / \mathrm{kg}$ recomendados por Maletto ${ }^{3}$ e estabelecidos pelo $\mathrm{NRC}^{7}$. Comparando-se esses resultados com os obtidos por Marçal et al. ${ }^{11}$ em amostras de suplementos minerais no Paraná, que variaram de 16,0 mg/kg a 625,0 mg/kg, verifica-se que o autor também obteve valores elevados e muito próximos aos desta pesquisa. Nesse sentido, há que se considerar que existem suplementos minerais contaminados com metais pesados sendo consumidos por bovinos não só no Estado de Goiás, mas em outros estados do país.

Isso é preocupante, pois esses metais se acumulam nos organismos dos animais produtivos, e pode ser repassado ao homem posteriormente por meio da cadeia alimentar. Além disso, deve-se ressaltar a contaminação itinerante das pastagens por meio das fezes dos bovinos, tendo em vista que grande parte dos contaminantes, especialmente o chumbo, elimina-se pelas fezes, e também acumulam no organismo.

\section{Cádmio}

$\mathrm{Na}$ tabela 4, verifica-se que houve diferença significativa $(\mathrm{P}<0,05)$ entre as médias de cádmio em suplementos minerais comercializados em Goiás. Embora o cádmio em suplementos minerais e em outros produtos possua a tendência de ser encontrado em menores concentrações que o chumbo, acredita-se que o teor mínimo e máximo são preocupantes, visto o fato de ser cumulativo no organismo humano e animal. Ao contrastar os dados com os obtidos em outro estudo ${ }^{11}$, nota-se que as misturas de sal mineralizado utilizadas para alimentação de bovinos acham-se contaminadas por substâncias inorgânicas nocivas à saúde animal, especialmente chumbo e cádmio em concentrações acima do máximo citado na literatura - 30,0 mg/Kg para chumbo, e 0,5 mg/Kg para o cádmio ${ }^{4,7}$. 
Tabela 4. Teores de cádmio (mg/Kg) em suplementos minerais para bovinos comercializados, Estado de Goiás.

\begin{tabular}{|c|c|c|c|c|c|}
\hline Parâmetro* & \multicolumn{5}{|c|}{ Mesorregião } \\
\hline & Noroeste & Norte & Centro & Leste & Sul \\
\hline Média & $1,731^{*} \mathrm{ab}$ & $0,906^{* a}$ & $1,061^{* a}$ & $1,356^{*} \mathrm{ab}$ & $4,905^{* b}$ \\
\hline $\begin{array}{c}\text { Desvio } \\
\text { padrão }\end{array}$ & 0,92 & 0,88 & 5,37 & 2,10 & 1,23 \\
\hline CV (\%)c & 62,0 & 59,0 & 160,0 & 159,0 & 87,0 \\
\hline Mediana & $1,73^{*}$ & $1,45^{*}$ & $12,17^{*}$ & $1,31^{*}$ & $2,24 *$ \\
\hline $\begin{array}{c}\text { Amplitude } \\
\text { total }\end{array}$ & $2,30^{*}$ & $1,90^{*}$ & $21,65^{*}$ & $1,10^{*}$ & $3,47^{*}$ \\
\hline Mínimo & 0,56 & 0,50 & 0,35 & 0,79 & 0,63 \\
\hline Máximo & $2,86 *$ & $2,40^{*}$ & $22,0 *$ & $1,87 *$ & $3,97 *$ \\
\hline
\end{tabular}

*Teores acima do $\mathrm{LMR}^{4,7}$. a,b Em uma mesma linha valores seguidos de uma mesma letra não diferem significativamente entre si (Tukey, $\mathrm{p}<0,05$ ). ${ }^{\mathrm{c}} \mathrm{CV}=$ coeficiente de variação.

A mediana também apresentou resultado elevado semelhante ao teor médio entre as amostras colhidas nos municípios. Por outro lado, o valor máximo obtido em duas amostras, sendo uma na mesorregião Centro Goiano 22,0 mg/Kg e outra no Sul Goiano 5,5 mg/Kg, revelaram teores abaixo dos obtidos por Marçal et al. ${ }^{11}$, que encontraram valores que variavam de $2,0 \mathrm{mg} / \mathrm{kg}$ a $57,0 \mathrm{mg} / \mathrm{Kg}$ para o cádmio. Os valores encontrados para cádmio variaram de $0,50 \mathrm{mg} / \mathrm{Kg}$ (menor valor) a 22,0 mg/ Kg (maior valor). Devido à alta toxicidade do cádmio, os níveis de ação citados na literatura e estabelecidos na legislação são sempre menores que os do chumbo, mesmo porque a concentração de cádmio possui tendência de ser em menor teor ${ }^{9}$.

Das mesorregiões em estudo, a do Sul Goiano foi a que apresentou o maior teor de cádmio nos suplementos minerais. Há evidências de que os suplementos minerais comercializados nas regiões que apresentaram maior concentração de resíduos tóxicos são exatamente os que foram produzidos, utilizando ingredientes de origem mineral com alto teor de impureza e de baixa qualidade.

Das 50 amostras de suplementos minerais analisadas, 79\% apresentaram valores de cádmio acima de 0,5 mg/ $\mathrm{kg}$ recomendado por Maletto ${ }^{3}$. O menor valor obtido foi 0,072 mg/kg, e o maior, 20,0 mg/kg. Comparando estes resultados com os obtidos por Marçal et al. ${ }^{11}$ em amostras de suplementos minerais no Paraná, que variaram de 2,0 $\mathrm{mg} / \mathrm{kg}$ a $57,0 \mathrm{mg} / \mathrm{kg}$, verifica-se que houveram valores mais elevados que os resultados encontrados neste estudo.

\section{Solubilidade do fósforo em ácido cítrico}

A Tabela 5 contém os dados relativos à porcentagem de solubilidade do fósforo em ácido cítrico a $2 \%$ em suplementos e misturas minerais para bovinos no Estado de Goiás. Percebeu-se que não houve diferença significativa $(\mathrm{P}>0,05)$ entre as médias de solubilidade do fósforo em suplementos minerais comercializados em Goiás.

Tabela 5. Teores da porcentagem de solubilidade do fósforo em ácido cítrico a $\%$ em suplementos minerais para bovinos comercializados, Estado de Goiás.

\begin{tabular}{|c|c|c|c|c|c|}
\hline Parâmetro* & \multicolumn{5}{|c|}{ Mesorregião } \\
\hline & Noroeste & Norte & Centro & Leste & Sul \\
\hline Média & $81,0 * a$ & $78,9 * a$ & $83,6 * a$ & $81,8^{* a}$ & $74,6 * a$ \\
\hline $\begin{array}{c}\text { Desvio } \\
\text { padrão }\end{array}$ & 5,84 & 15,64 & 13,3 & 2,13 & 20,0 \\
\hline CV (\%)b & 5,70 & 19,55 & 16,9 & 2,73 & 25,97 \\
\hline Mediana & 91,0 & $80,0 *$ & $72,0 *$ & $79,0 *$ & $76,5^{*}$ \\
\hline $\begin{array}{c}\text { Amplitude } \\
\text { total }\end{array}$ & 98,0 & 96,0 & 98,0 & 90,0 & 99,0 \\
\hline Mínimo & $84,0 *$ & $64,0 *$ & $50,0 *$ & $75,0 *$ & $49,0 *$ \\
\hline Máximo & 98,0 & 96,0 & 98,0 & 90,0 & 99,0 \\
\hline
\end{tabular}

*Teores abaixo do padrão mínimo $(90 \%)^{31}$. ${ }^{a}$ Em uma mesma linha valores seguidos de uma mesma letra não diferem significativamente entre si (Tukey, $\mathrm{p}<$ 0,05). ' ${ }^{\text {}} \mathrm{CV}=$ coeficiente de variação.

Observou-se que as amostras de suplemento e sal mineralizado mostraram de modo geral, percentuais de solubilidade abaixo do mínimo estabelecido de 90\% pelo $\mathrm{MAPA}^{31}$, revelando um aspecto interessante para esta pesquisa, porque sinaliza uma tendência evidente e rotineira do uso de fontes alternativas para o fósforo, tentando minimizar os custos dessas formulações, com o intuito de garantir vendas. Mas isso traz como consequências, prejuízos para a saúde e produtividade animal, devido à baixa qualidade em termos de impurezas e disponibilidade do elemento fósforo. Esta tendência torna-se importante sob o ponto de vista sanitário e de produtividade, pois aproximadamente $80 \%$ dos custos com a suplementação mineral bovina são atribuídas ao fósforo, devido a sua larga utilização para suprir as deficiências de pastagens em nosso Estado.

Entre as amostras analisadas das mesorregiões citadas, as do Sul Goiano foram as que apresentaram menores porcentagens de fósforo solúvel nos suplementos minerais. Fundamentado neste resultado, pode-se perceber 
que os suplementos minerais nessa mesorregião foram os que apresentaram maiores indícios de contaminação com elevados teores de chumbo e cádmio, exatamente porque foram produzidos utilizando ingredientes com alto teor de impurezas e de baixa qualidade.

Os resultados demonstraram a necessidade de monitoramento junto aos fabricantes e comerciantes, pois algumas misturas minerais podem ser eminentemente perigosas, devido aos efeitos cumulativos tóxicos dos metais pesados cádmio e chumbo aos bovinos.

\section{Conclusões}

Nas condições deste estudo e em função dos resultados obtidos, conclui-se que a maior parte dos teores médios de cádmio e chumbo em suplementos minerais para bovinos em Goiás, estão acima do LMR encontrado nas literaturas citadas e estabelecido na legislação. Em relação ao chumbo, quase metade das amostras das mesorregiões estudadas apresentaram teores médios acima do regulamentado, e para o cádmio mais da metade das amostras estavam em desacordo com a literatura. Isso evidencia a presença de resíduos tóxicos acima do aceitável para os bovinos, bem como para a saúde humana, visto que os homens podem se alimentar desta carne em seu dia a dia.

A baixa solubilidade do fósforo na maioria dos suplementos sugere uso frequente de fontes não convencionais deste elemento na elaboração das misturas. Assim, o rebanho pode obter uma alimentação deficiente em nutrientes de forma geral, com presença residual de contaminantes, o que não é recomendável. Essa situação seria um quadro favorável apenas aos fabricantes dos produtos que poderão ganhar lucros por fornecerem material com menor custo, e consequentemente com baixa qualidade.

\section{Referências}

1. IBGE. Calendário Oficial de Exposições e Feiras Agropecuárias. Ministério da Agricultura, Pecuária e Abastecimento. Sociedade Brasileira de Medicina Veterinária. Efetivo Pecuário do Estado de Goiás. Brasília, 2008.

2. Brasil. Ministério da Agricultura, Pecuária e Abastecimento. Secretaria de Defesa Agropecuária. Portaria SRD n ${ }^{\circ} 20$ de 06 de julho de 1997. Liberou o uso de fontes alternativas de fósforo a partir de fosfatos de rochas. Brasília. 1997.
3. Maletto, S. Correlação da nutrição mineral e a sanidade. In: SEMINÁRIO SOBRE NUTRIÇÃO MINERAL, São Paulo. Anais... São Paulo, 1986.

4. Association of American Feed Control Officials Incorporated. Official guidelines for contaminant levels permitted in mineral feed ingredients. Indiana: AOAC. 2001.

5. Marçal, W.S.; Gaste, L.; Liboni, M.; Pardo, P.E.; Nascimento, M.R.; Hisasi, C.S. Lead Concentration in mineral salt mixtures used in beef cattle food supplementation in Brazil. Vet. Arch., 1999, 69, 6 .

6. Marçal, W.S.; Campos Neto, O.; Nascimento, M.R.L. Valores sanguíneos de chumbo em bovinos Nelore suplementados com sal mineral naturalmente contaminado por chumbo. Ciênc. Rural., Santa Maria, 1998, 28, 1.

7. NRC. National Research Council. Subcommittee on Mineral Toxicity in Animals Nutrient requirements of beef cattle. Washington: National Academy of Science, 1996.

8. Andrigueto, J. M.; Perly, L.; Minardi, I.; Gemael, A.; Fleming, J. S.; Souza, G. A.; Bona Filho, A. Os princípios nutritivos e suas finalidades. In: Nutrição animal. 4 ed. São Paulo: Nobel, 1990. p. 189-255.

9. Gonçalves, J. R. Determinação de metais pesados em leite integral pasteurizado no Estado de Goiás. 1999. 80 f. Dissertação (Mestrado em Ciências Animais) - Escola de Veterinária, Universidade Federal de Goiás, Goiânia.

10. Allen, J.D. Minerals in animal feed. Industrial Minerals. London, 292, p. 35-39. 1992

11. Marçal, W.S.; Sousa, A. M.; Nascimento, M.R.I.; Carvalho, M.C. Valores de chumbo inorgânico em suplementos minerais para bovinos comercializados no Estado de Goiás. Arq. Inst. Biol., 2004, 71, 1 .

12. Junqueira, O. M. Metais pesados contaminam carne. Avicultura \& Suinocultura Industrial, São Paulo, 1993, 38.

13. Nunes, R. C.; Kronka, R. N; Sobestiansky, J; Lopes, E. L.; Gonçalves, J. R. Retirada dos suplementos micromineral e/ ou vitamínico da ração de suínos em fase de terminação. Desempenho, níveis de minerais nos metacarpos e custo de ração. Ciência Animal Brasileira, 2002, 3, 1.

14. Campos Neto, O.; Marçal, W.S. Os fosfatos na nutrição mineral de ruminantes. Revista dos Criadores, 1996, 793.

15. Lobão, A. O. Mineralização de bovinos de corte. In: Simpósio Sobre Pecuária de Corte, Presidente Prudente. Anais... Jaboticabal: UNESP, 1977.

16. Pansard, N. T. Informações sobre fiscalização em suplementos minerais pelo Ministério da Agricultura, Pecuária e Abastecimento. Londrina, 2002.

17. Villegas-Navarro, A.; Elena Bustos, O.D.M.; R Eyes Raymond, A.; Dieck, T.A.; Reyes, J.L. Determination of lead in paired samples of blood and synovial fluid of bovines. Experimenthal and Toxicologic Pathology, 1993. 
18. Marçal, W.S. Valores sanguíneos de bovinos nelore em pastejo de Brachiaria decumbens, suplementados com sal mineral naturalmente contaminado por chumbo. 1996. $92 \mathrm{f}$. Tese (Doutorado em Ciência Animal) - Faculdade de Medicina Veterinária e Zootecnia, Universidade Estadual Paulista, Botucatu.

19. Rosa, I. V. Fosfato natural como suplemento de fósforo para bovinos. In: VALLE, E.R. et al. Coletânea de seminários técnicos 1986/88. Campo Grande: Embrapa, 1989.

20. Butolo, J. E. Qualidade de Ingredientes na Alimentação Animal. Campinas: Colégio Brasileiro de Nutrição Animal. 2002.

21. Maracek, I.; Lazar, L.; Dietzova, I.; Korenekova, B.; Choma, J.; David, V. Residues of heavy metals in cow reproductive organs and morbidity of cattle in the fallout region of a metallurgical plant. Vet. Med., 1998, 43, 9.

22. Goiás. Anuário Estatístico do Estado de Goiás. Seplan. Goiânia, 2006.

23. American Society for Testing and Materials. Annual book of ASTM Standards. Philadelphia: ASTM, 1980.

24. Eaton, C.L.S.; Greenberg, A.E.; Trussell, R.R. (Eds.). Standard methods for the examination of water and wastewater. Washington: APHA, 1995.

25. SAS. Statistical Analysis System. System for Windows, release 6.12. Cary, NC: 01 CD-ROM, 2002.

26. Brasil. Sindirações. Compêndio Brasileiro de Alimentação Animal/Ministério da Agricultura e Reforma Agrária. Métodos analíticos de controle de alimentos para uso animal. São Paulo. 2009.

27. Leite, F. Validação em análise química. 2. ed. Campinas: Editora Átomo, 1998. 124 p.

28. Radostits, O. M.; Gay, C. C.; Blood, D. C.; Hinchcliff, K. W. Doenças causadas por substâncias químicas inorgânicas e produtos químicos utilizados nas fazendas. In: Radostits, O.M.; Gay, C.C.; Blood, D.C.; Hinchcliff, K.W. Clínica veterinária: um tratado de doenças dos bovinos, ovinos, suínos, caprinos e equinos. 9. ed. Rio de Janeiro: Guanabara Koogan, 2000.
29. Buture, I. O.; Marçal, W. S. Teores de chumbo e cádmio em suplementos minerais para bovinos comercializados no Estado do Paraná. Archives of Veterinary Science, 2005, 10, 1.

30. Viana, J. A. C. Fontes de sais minerais para bovinos e o desafio de suplementos de fósforo no Brasil. In: Simpósio Sobre Nutrição De Bovinos, 3. Piracicaba. Anais... Piracicaba: FEALQ, 1985.

31. Brasil. Ministério da Agricultura, Pecuária e Abastecimento. Secretaria de Defesa Agropecuária. Portaria nº 08 e 20 de 13 de dezembro de 1988. Estabelece os padrões para misturas minerais para bovinos. Brasília. 1988.

\section{José R. Gonçalves ${ }^{1,2}$, Renata M. Gonçalves ${ }^{3 *} \&$ Raniery M. Gonçalves².}

${ }^{1}$ Faculdade de Tecnologia SENAI Roberto Mange, Rua Engenheiro Roberto Mange, n. 239, Bairro Jundiaí, CEP 75113-630, Anápolis, GO.

${ }^{2}$ Laboratório Nacional Agropecuário do Estado de Goiás. Ministério da Agricultura, Pecuária e Abastecimento. Rua da Divisa s/n, Setor Jaó, CEP 74674-025, Goiânia, GO.

${ }^{3}$ Faculdade Anhanguera de Anápolis, Avenida Universitária, 683, Centro, CEP 75080-150, Anápolis, GO.

*e-mail: renata.nut@gmail.com 